\title{
Patient and Health System Related Factors Associated with Non-Adherence to Antihypertensive Medication among Patients at Chuka Referral Hospital, Kenya
}

\author{
Charity Gikunda*, Lucy Gitonga, Paul Kamweru \\ Chuka University, Tharaka-Nithi County, Kenya \\ Email: *chtygida@yahoo.com
}

How to cite this paper: Gikunda, C., Gitonga, L. and Kamweru, P. (2021) Patient and Health System Related Factors Associated with Non-Adherence to Antihypertensive Medication among Patients at Chuka Referral Hospital, Kenya. Open Journal of Clinical Diagnostics, 11, 19-46. https://doi.org/10.4236/ojcd.2021.112002

Received: March 6, 2021

Accepted: May 5, 2021

Published: May 8, 2021

Copyright $\odot 2021$ by author(s) and Scientific Research Publishing Inc. This work is licensed under the Creative Commons Attribution International License (CC BY 4.0).

http://creativecommons.org/licenses/by/4.0/

\begin{abstract}
Background: Non-adherence to hypertensive medication continues to become a contributing factor to hypertensive complications like stroke, heart attacks, kidney disease heart failure. Associated factors to non-adherence are complex, are both internal and external to the patient and are difficult to extrapolate. Reports from Chuka referral hospital records showed that in 2016 there were 140 patients with hypertensive complications from $560 \mathrm{pa}$ tients who attended the medical clinic that year. Objective: This study sought to explore the patient's related factors that are associated with non-adherence to hypertension medication. Methods: This is a descriptive study design of ( $\mathrm{N}=575)$ people among them doctors, pharmacists, nurses, record officers and hypertension patients. Simple random sampling for patients $(n=81)$ and census sampling for health care workers was done and data collected using questionnaires and interview schedules between April $4^{\text {th }}$-May $30^{\text {th }} 2019$. Inferential and descriptive statistics were used for data analysis, aided by SPSS version 25. Results: $64 \%$ of the patients stated that they had missed medication. A significant negative correlation $\left(r_{p b}=-0.23, p<0.05\right)$ between age and non-adherence, significant positive correlation with monthly income $\left(r_{p b}=\right.$ $0.24, p<0.04)$, non-significant relationship between non-adherence and marital status $\left(r_{p b}=-0.13, p=0.25\right)$ and patients' level of education $\left(r_{p b}=-0.06\right.$, $p=0.57)$. The overall model of health system related factors were found to be significant $(p<0.05)$ and this included; quality of health service, physician patient relationship, stock out, health education, and availability of medicine $(p=0.012)$. Conclusion: Lacks of funds, unavailability of drugs are the leading factors to regimen completion. This could be easily be addressed by the government.
\end{abstract}




\section{Keywords}

Hypertension, Non-Adherence, Medication, Inhibiting Factors, High Blood Pressure, Patients Characteristics

\section{Introduction}

Hypertension, or elevated blood pressure, is the leading risk factor for the development of cardiovascular disease (CVD) the leading cause [1] of death worldwide [2] [3]. Approximately $45-81$ percent of patients worldwide with hypertension (HPT) have poor blood pressure control [4]. An estimated 1.13 billion people worldwide have hypertension, most (two-thirds) living in low- and middle-income countries [5]. Further WHO states that the continent of Africa has the highest hypertension prevalence (46\%) for both the male and females [6]. Hypertension prevalence of $28.7 \%$ in Kenya was reported [7], a burden to low resource countries like Kenya [8].

One way of managing hypertension (HPT) to an optimal blood pressure control level is by the use of antihypertensive medication. The success of antihypertensive drugs is well recognized and has been measured in terms of reduction of overall relative risk of cardiovascular disease and other hypertensive complications like stroke and as well as lower healthcare costs [9] [10] [11] [12]. Compliance with hypertension drugs is a key factor to avoiding poor controlled hypertension and the possibilities of developing complications linked to hypertension for example renal failure, heart attacks, strokes and eye complications which are dangerous and can lead to sudden death [13] [14]. Non-adherence to hypertensive medication is the major impendent in the fight against hypertensive complications like heart attacks, heart failure, stroke and other complications [15] [16] [17] [18].

The problem of non-adherence to medication is unlikely to end soon [19]. A number of analyses have revealed that in developed countries, non-adherence to long term therapeutics including HPT therapy in the population, has a high prevalence [20].

Only $29 \%$ of patients under treatment with antihypertensives drugs had their BP contained in the recommended levels of $<140 / 90 \mathrm{mmHg}$ [21]. Non-adherence to hypertensive medication in many hospitals is characterized by failure to refill the regimen, failing to honor appointments, patients stopping the medication when they felt better or due to the side effects. Earlier studies identified multifactorial patients and health care systems related factors that lead to non-adherence to antihypertensive medication that includes patient's beliefs, income, age, gender and education [20] [22]-[27].

Such demographic investigations are essential, but they have a tendency to limit comprehension of the multifaceted set of influences that in collaboration or on their own effect non-compliance in regards to the termination of taking me- 
dication or omitting dosages [28].

The WHO acknowledged that inadequacies and complexity with healthcare systems contribute to obstacles in optimum adherence to medication [29].

Health system related factors include quality of health care services, distance, physician patient relationship and stocks out, guideline for management, cost of drug and distance to the health facility. Patients' associated factors include social-economic status, patients' beliefs, race/ethnicity, health literacy, and others [17].

The development of a sustainable, systematic healthcare system in Kenya is designed to benefit all the country citizens, including prevention of common health issues and disease-related complications, and to ensure public wellbeing is the focus of the healthcare service. The government in Kenya is intent upon creating mechanisms to improve and implement comprehensive health service programmes through the Ministry of Health ( $\mathrm{MOH})$, as well as other related health organizations [30].

Accordingly, the $\mathrm{MOH}$ has adopted a number of programmes and health policies designed to prevent, detect, evaluate and treat non-communicable diseases, one of which is hypertension [31].

Healthcare system sustenance to patients with hypertension has a substantial role in enhancing adherence to HPT treatment. Support related to patients with hypertension in relation to adherence activities contemplates elements of providing information that is supporting or helpful in regards to the recommended medications. Successful management of hypertension relies on comprehension, endurance of hypertension care, and link with health education. The chief emphasis of provision of information resources or educational support is to benefit patients with hypertension to follow medical instruction on drugs and highlight the significance of performing health examinations and screening periodically [32]. Providing educational sessions or educational material through conduction of educational interventions, provide patients with facts concerning their health condition and treatments which can help to better HPT treatment compliance [33].

Physician communication is a helpful predictor of adherence to medication thus if physician communication is poor can result to non-adherence to medication [34] Good communication between patient and clinicians led to a good patient-client relationship which is a significant predictor increasing adherence to medications [35].

This study was thus expected to identify some of these factors influencing non-adherence to antihypertensive medication at the local level due to the effects of patients and health system.

The research objectives were to describe the association between patients' characteristics and non-adherence to hypertension medication and describe system related factors that are associated with non-adherence to hypertension medication at Chuka Referral Hospital. The research question posed for this study 
was, "what are the health system and patient related factors that contribute to antihypertensive medication non-adherence in a sample drawn from hypertensive patients visiting Chuka referral hospital".

\section{Theoretical Framework}

This study was grounded on behavior change theory known as theoretical domain framework (TDF) [36]. The TDF was chosen because it incorporates 33 behavior change theories and has related tools to support the application of behavior change interventions. TDF is able to acknowledge and enlighten the progress of the intervention expected [37].

Many adherence interventions to date have not been effective [38]. Intervention that is effective has often involved a level of difficulty that has been too expensive and challenging to apply in practice [38] and thus clarifications and models of medication adherence/non-adherence have changed over the years. Previous studies focused on the part of patient and doctor statement and its outcome on satisfaction of patient, comprehension and forgetfulness as main factors of succeeding adherence to treatment [39]. Though, research in health behavior has reliably proven that the delivery of facts alone is not an actual means to modification of behaviour, and thus studies have now progressed onto models and approaches which concentrate on beliefs of patients' planning abilities and motivation as the main descriptive variables. The models include self-regulatory models and social cognition models which put emphasis on the importance of the opinions that the persons have in regard to their ailment and management as well as their own capability to track the advice and treatment recommended [40].

Growth in behavior change comprises also of participants who records and monitors their behavior [40] and these interventions were found to be more effective and significantly at supporting healthy eating and physical activity more than interventions that the technique was not included [40]. The growth of classification of behavior change techniques lead to new techniques of theorizing the factors which determine or explain person's health associated behaviors and at the center of this new methodology is a psychological model for explanation of human behavior that is wished to include the array of technique that will be included in change [40].

The classifications include Capability, Opportunity and Motivation (COM) B behavior. These classifications were established with quotation to current theories of behavior change. A consensus meeting was held by behavioural theorists in the United State of America which reflected the fundamentals for the enactment of an identified volitional behavior They proposed that classifications were set as a preliminary directive to select interventions that were more effective [40].

The model postulates that there are relations amongst 3 models to include Capability, Opportunity and Motivation (COM) which results in the enactment of Behavior (B) thus this can also offer justifications for reasons of not engaging 
in acclaimed behavior. To effectively accept and proceed with long-term treatment regimen like hypertensive regimen, behavior change is required and hence behavior change ideologies can be used to hasten the acceptance of medication adherence. The effectiveness of behavior-changing interventions, aimed at each individual stage of change has been established in numerous health behavioral areas and interventions include monitoring devices, reminder techniques and rewards. Which are very significant for patients in advanced stages of behavior change, but patients in earlier stages require interventions that are consciousness-raising aimed at consciousness of the advantages of treatment.

Behavior change is crucial to promoting hypertension adherence and improving the health outcomes [36]. For example, behaviors may be those of healthcare providers such as evidence-based practice implementation, of patients, such as adhering to medication or of the general population, such as cessation of smoking and increasing physical activity. In spite of high-level noble work to promote the execution of evidence-based practice by developing field of implementation in science and Clinical Effectiveness Research Agenda Group (CERAG, 2008) [41] Execution remains variable, with various individual and health system factors influencing healthcare providers' behavior. These factors include the accessibility of evidence, relevance to exercise, the distribution of guideline and evidence, motivation of the individual, clarity of roles and practice, the culture of specific healthcare practices and the ability to preserve current changes [42].

Hypertensive medication adherence can be attained through changing health care workers' behavior [43]. If interventions are based on principle of change of behavior, changing is easy but if there are no principles then change of behaviour is hard [44]. Behavior change interventions informed by the theory are more effective than those that are not [45]. TDF is a theoretical framework rather than a theory thus it delivers a theoretical lens through which factors influencing behavior are viewed, these include; the affective, cognitive, social, and environmental effects on behavior.

\section{Materials and Methods}

\subsection{Study Population}

The study was conducted at Chuka Referral Hospital in Tharaka Nithi County between April $4^{\text {th }}$-May $30^{\text {th }}$ 2019. Chuka referral Hospital is a Government health facility located in Chuka town in Tharaka-Nithi County. The county borders Meru county to the north and northeast, Kitui County to the east and southeast, Embu County to the south and southwest. The division lies between latitudes $0^{\circ} 15^{\prime} 0^{\prime \prime}$ and longitudes $37^{\circ} 1^{\prime} 45^{\prime \prime}$. Descriptive design was chosen to collect data concerning non-adherence to hypertension medication in order to draw a valid conclusion from the facts discovered [46].

The study population comprised 575 people among them doctors, pharmacists, nurses, record officers and hypertension patients, who had been using the antihypertensive treatment and attending Chuka Hospital hypertension clinics. 
Table 1. Distribution of the target population by category $(\mathrm{N}=575)$ obtained from the Chuka referral hospital registry [48].

\begin{tabular}{cc}
\hline Population & Frequency \\
\hline Patients & 560 \\
Doctors & 3 \\
Pharmacists & 5 \\
Nurses & 2 \\
Record officers & 5 \\
Total & 575 \\
\hline
\end{tabular}

Table 1 presents the distribution of population that the study targeted. The study used simple random sampling to select study sample size for hypertensive patients and census taken for health workers that include: doctors, pharmacists, record officers and nurses attached to the medical outpatient clinic because they are too few to sample. The sample size was derived according to Nassiuma [47].

The study population included all hypertensive patients on follow-up at the hospital medical clinics. Patients aged 18 years and above were eligible to participate in this study. Enrolment of study participants was carried out at the beginning of each clinic day. This was done at the registration desk where all patients report for their appointments. The study used simple random sampling to select a subsample of the patients from a population of 560. A list of accessible patients was prepared and then the number to be interviewed was determined from the attendance list. Every client was given a number which was placed in a container and then the number was picked randomly, the patient corresponding to the number picked was included in the sample.

\subsection{Sample Size}

The size of the sample was derived according to Nassiuma [47] whereby a coefficient of variance at most is $30 \%$ of the population which is considered adequate for most surveys.

$$
\text { Sample size } n=\frac{N C^{2}}{C^{2}+(N-1) e^{2}}
$$

where

$$
\begin{aligned}
& n=\text { sample size } \\
& N=\text { population from which sample is obtained } \\
& C=\text { coefficient of variance } 30 \% \\
& e=\text { standard error } 0.02 \\
& \qquad n=\frac{560\left(0.3^{2}\right)}{\left(0.3^{2}\right)+(560-1)\left(0.02^{2}\right)}=161 \text { patients }
\end{aligned}
$$

The total number of respondents was 161 patients and 15 health care workers totalling 174 .

\subsection{Data Collection and Analysis}

A semi structured questionnaire that was reviewed for face and content validity 
by peers and expert in the Department of Science and Engineering at the university. Pilot study data aided instrument improvement and reliability analysis. The reliability coefficient of variables was 0.7 and thus the instrument was considered reliable. Descriptive analysis was used to obtain frequencies and percentages. Interview schedules were analysed through open coding and results were presented by the use of charts, tables and graphs. Binary logistic regression models were used to analyze the association between the patients' related and health related factors allied with medication non-adherence. The Nagelkerke R2 was tested to measure the percentage of difference accounted for by the independent variables [49]. Predicted probabilities of an event occurring were determined by Exp $(\beta)$. The Wald statistic was used to measure the support of individual predictors or the significance of individual coefficients in the model. A p-value of less than 0.05 was considered statistically significant for this study.

\subsection{Study Limitations}

This study was conducted in government referral Hospitals in Tharaka Nithi County and did not include patients who attended private Hospitals. Therefore results cannot be generalized to all hypertension patients in the county. However, the results have important insights for the same hospitals within the same characteristics. Self-reporting of the questionnaire could introduce recall bias by either over-reporting or under-reporting depending on the patient's behaviour in the recent past. However, the researcher was clarifying the questions when asking participants.

\subsection{Inclusion Criteria}

Hypertensive patients aged 18 years and above and consenting to participate in the study.

Patients on follow-up at the medical outpatient clinic.

Patients on treatment for over 6 months.

All doctors, nurses, pharmacists and record officers working in the hypertensive clinic.

\subsection{Exclusion Criteria}

Patients declining consent for participation and below 18 years.

Very sick patients warranting admission.

\section{Results and Discussion}

The overall questionnaire response rate was $50 \%$, (81/161), of the patients who were engaged in the study. In addition, 10 medical staff members participated in the interview, intended to gather information to elaborate the quantitative facts. The involvement of an expanded spectrum of stakeholder involving patients, nurses, pharmacists, and doctors illuminates the representativeness of the sample and thus, the external validity of the results. 


\subsection{Profile of the Respondents}

In an attempt to profile the research participants, the study focused on their age, gender, education level, occupation and marital status. First, the study wanted to know the gender of the participants. The findings are shown in Figure 1. The finding indicates that most of the respondents (68\%) were female while $32 \%$ were male.

The participants were also asked to give their ages. Figure 2 shows percentage distribution of the respondents on the basis of age. The respondents' ages ranged between 20 and 90 years. The category with the highest number was between 60 70 years $(23.2 \%)$, followed by $40-50$ years $(20.5 \%)$, and at third place in the group with 50 - 60 years (17.8\%). The respondents above 50 years of age totaled $57.6 \%$. The study also wanted to know the profile of the respondents in terms of their marital status. The findings are tabulated in Figure 3. The status of marriage of the research participants varied from unmarried $(2.5 \%)$ to married (69.1\%). In between these extremes are the windowed (7.4\%), separated (8.6\%) and those cohabiting (12.3\%).

The education levels are found to influence much decision-making. The study, therefore, desired to know the highest level of education of the participants, and the findings are revealed in Figure 4. Most of the participants (75.3\%) knew how to read and write, hence capable of following doctor's directions and adhering to hypertension medication. Sixty-nine percent (69\%) had secondary and post-secondary education and only $17.3 \%$ had no education. Figure 5 show the

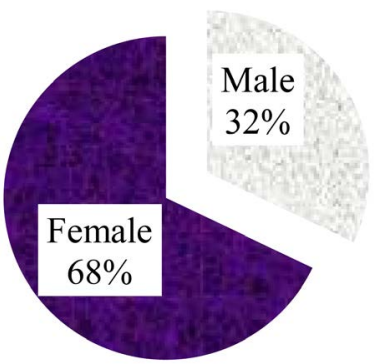

Figure 1. Gender of the respondents $(n=80)$.

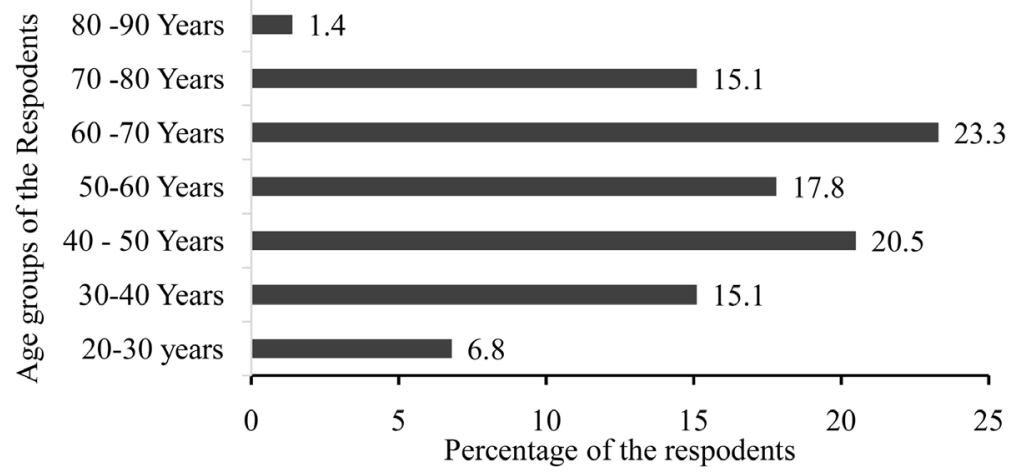

Figure 2. Age groups of the respondents' $n=81$. 


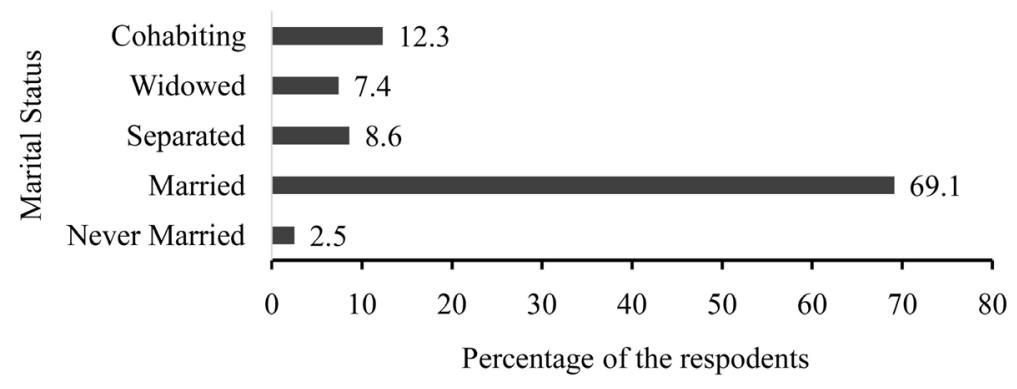

Figure 3. Marital status of the respondents $(n=81)$.

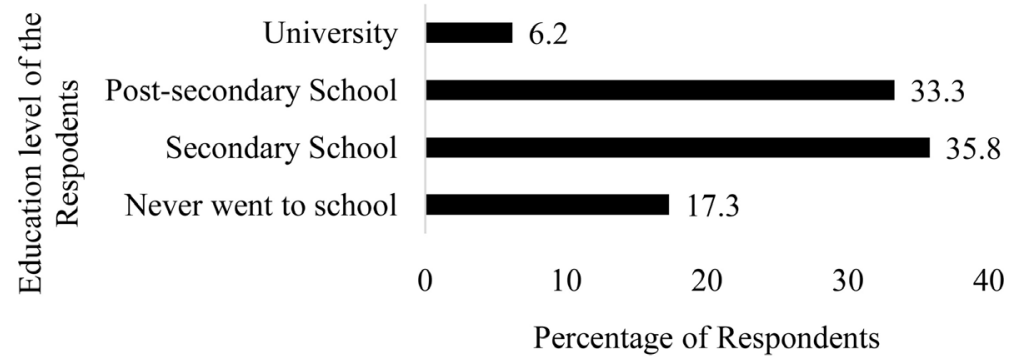

Figure 4. Level of education for the participants $(n=81)$.

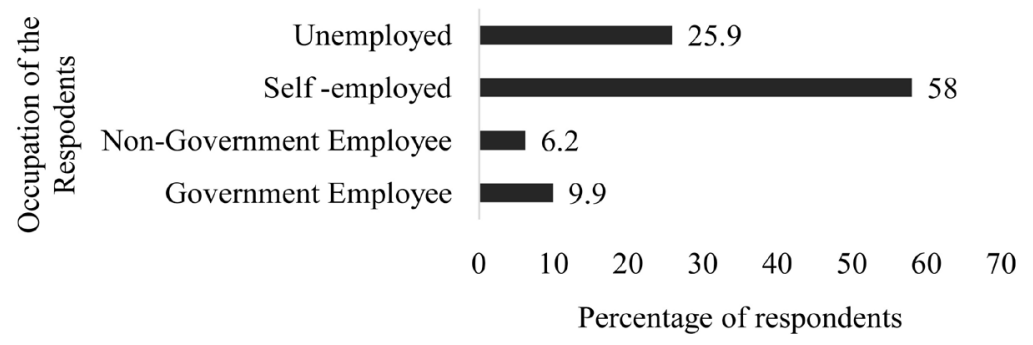

Figure 5. Distribution of respondents by occupation $(n=81)$.

frequencies and percentages of respondents based on their occupation. The results suggest that the patients fell under four categories of employment, government employees, private firms employees, self-employed and unemployed.

The research study found that over half of the participants (58\%) were selfemployed. This suggests that most of the hypertension patients in the county are self-employed either working on their farms or in private business. Surprisingly, less than $10 \%$ of the patients were government employees.

Figure 6 shows the distribution of participants depending on their levels of monthly income. The income levels were grouped in classes of ksh 10,000. A majority (54.3\%) earned less than ksh 10,000 per month.

\subsection{Association between Respondents Profile and Non-Adherence to Hypertensive Medication}

\subsubsection{Gender of the Respondents}

Research has shown that gender is one of the most significant factors influencing behavior in health including medication adherence [50]. More studies have shown that women visit care providers to a greater extent than does men, for 


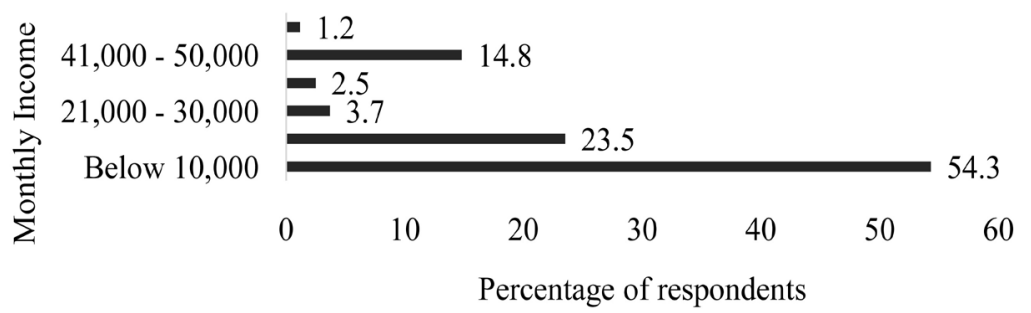

Figure 6. Distribution of respondents by income $(\mathrm{n}=81)$.

both physical and mental health concerns [51] [52].

Table 2 presents the association between age, gender, education level, marital status, and non-adherence to hypertensive medication $(\mathrm{n}=81)$. A Phi correlation among gender and non-adherence revealed no significant association (rpb $0.127, p=0.26$ ) between gender and antihypertensive medication non-adherence. The findings contradict the results of Courtenay [50] who found in their study that anti-hypertensive medication non-adherence is 1.3 times higher in male than in female patients. The research finding also contradicts results from a study conducted on Chinese immigrants in America investigating the association amongst cultural associated factors and socio-demographic associated factors in relation to adherence to hypertension medication which revealed that women had greater adherence than men [53].

\subsubsection{Age of the Respondents}

The current study findings revealed that most of the patients (57.6\%) were aged over 50 years thus elderly people have been found to be more non-adherent to medication than young people. The study results revealed a negative correlation $\left(r_{p b}=-0.271\right)$ between age and non-adherent to medication (Table 2). This implies that young ages relate to high levels of adherence. This can be interpreted to mean that elderly patients were more likely to miss drugs than young people. The study findings contradict the results of a prior study that investigated the relationship between adherence to medication by the patient and increasing age which put forward that older patients made fewer errors in non-adherence and were more regular in taking their prescribed treatments due to the influence of having more consistent daily schedules [54].

\subsubsection{Marital Status of the Respondents}

Majority of the participants (69.1\%) were found to be married. The point biserial test revealed a negative negligible relationship between non-adherence to medication and marital status $\left(r_{p b}=-0.12, p=0.25\right)$. Involvement of domestic relationship with a spouse did not contribute positively to adherence of antihypertensive. This contradicts a cross-sectional study at Duke University in the United States of America, which explored emotive well-being for a hypertensive individual who was unmarried in respect to their adherence to hypertensive medication which found that being married was related to a higher likelihood of adherence to hypertensive medication [55]. 
Table 2. Association between patients' characteristics and non-adherence to medication $(\mathrm{n}=81)$.

\begin{tabular}{cc}
\hline Characteristics & Non-adherence $\left(r_{p b}\right)$ \\
Age & $-0.271^{\star}$ \\
Gender & 0.127 \\
Education Level & -0.064 \\
Marital status & 0.129 \\
Economic status & $-0.241^{\star}$ \\
\hline
\end{tabular}

${ }^{*} p<0.05$.

It is perceived that married people should be more adherent than other forms of marital status because of the support from the spouses. A study that examined mediation between marital status and outcomes in individuals with heart failure revealed that unmarried individuals with heart failure had a higher risk of cardiac events than married patients [56].

\subsubsection{Education Level of the Respondents}

Regarding education, the study found that most of the patients $(75.3 \%) \mathrm{knew}$ how to read and write, this revealed an insignificant $\left(r_{p b}=-0.06, p=0.57\right)$ correlation between patients' education level and adherence to hypertension medication. Most of the respondents had basic education hence capable of following doctor's directions and adhering to hypertension medication. Patients with higher levels of formal education may have a better knowledge of the aim of maintaining their blood pressure, though a different study noted the increase in adherence with increasing educational status which was inconsistent with this study [57], however Arshia and others confirm the results where it was found out that non-adherence was high in the individuals who had more education years [20], thus this calls for collaborative work, not only clinicians but even other health care workers to include nurses clinicians, physicians, pharmacists and nutritionists have a significant part in the monitoring and educating individuals with hypertension. Plain language is advocated instead of technical language or medical jargon to aid in more understanding.

\subsubsection{Economic Status of the Respondents}

A point biserial test results (Table 2) revealed a positive correlation between the monthly income of the patients and medication non adherence $\left(r_{p b}=0.241, p=\right.$ $0.04)$. This means that an increase in the patients' income by one unit would result in an increase in adherence by 0.241 units. The study finding further revealed that the majority of the participants earned less than 10,000 shillings per month which are in line with a study done in the United States of America which showed that individuals with poor health management and low income were more non-adherent due to the of the struggle they encountered to seek out healthcare services or afford treatment [58] [59]. Thus Low levels of economic status are associated with high levels of non-adherence. 
Hypertension treatments are long-term medications that necessitate repeated refilling however one of the obstacles in medication adherence is the cost which obstructs the steadiness of medication for patients with low incomes [22]. The main reason for the present result is that not all prescriptions are obtainable in the hospital and thus patients have problems dealing with the cost of prescriptions. Research has previously indicated that poor treatment adherence which is cost-related may tell the meaning of necessity and offer an explanation for nonadherence to treatment [22]. Hypertension drugs vary in price from expensive to affordable [60] [61].

The role of individual economic status is relative to adherence to prescription as restricted to the capability to purchase the medications. In this study, education level did not matter as most participants had post-secondary education though many were still self-employed. Therefore, it is reasoned that individuals with high earnings are associated with better management of their health. Individuals with poor health management and low income had the struggle to afford drugs or even other services in health care. Low-income status was a problem related to poor adherence as was the case for low-income African Americans in the United States of America ([56] [57], and in individuals in urbanized communities in rural Eastern Uganda [62]. Therefore poor adherence was associated with low monthly earning for patients attending Chuka referral hospital.

\subsubsection{Employment Status of the Respondents}

The results of employment and association to ant hypertensive medication nonadherence can be argued by in availability of personal financial support that enables support to purchase of medicines and access of other medical services. The finding is in line with the study from Korea where patients with hypertension showed that employment was related to a greater likelihood of adhering to antihypertensive medication compared to unemployed or retired patients [63].

\subsection{Non-Adherence to Hypertension Medication}

Figure 7 depicts the frequencies and percentages of hypertension patients who are non-adherent to medication. The results show that $64 \%$ of the hypertensive patients had missed medication. The study sought to seek the reason(s) for this nonadherence, and this is discussed in the coming subsections. Table 3 reveals the categorized reasons, frequencies and percentages of patients with hypertension who are non-adherent to medication.

A significant majority (55.7\%) of respondents cited lack of funds as the major reason for non-adherence, $24.6 \%$ cited lack of time, $16.4 \%$ stated that they forgot, and 3.3\% thought they had healed. An investigation on the level of non-adherence with medication indicated that a majority of the hypertensive patients at Chuka Hospital were not adherent to hypertension medication. The results revealed that $64 \%$ of the patients with hypertension had missed medication due to lack of funds, forgetfulness, lack of time, forgetfulness and others thought they had healed. 


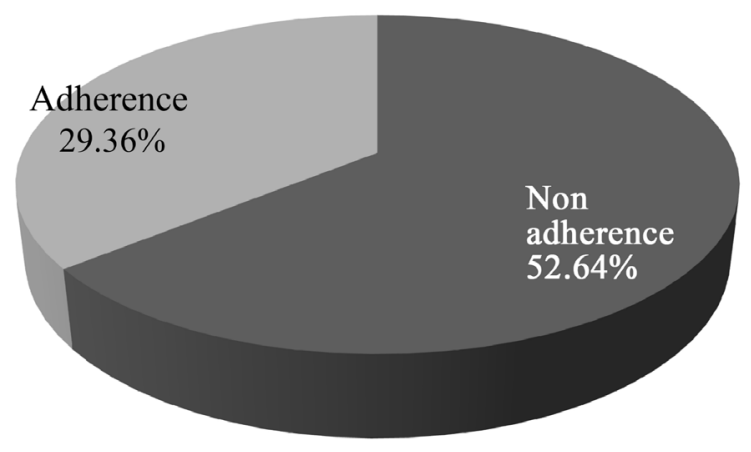

Figure 7. Distribution of respondents by non-adherence $(\mathrm{n}=81)$.

Table 3. Distribution of patients on reasons for non-adherence $n=81$.

\begin{tabular}{ccc}
\hline Reasons for non-adherence & Frequency & Percentage \\
\hline Lack of funds & 29 & 55.7 \\
Lack of time for refills & 12 & 24.6 \\
Forgetfulness & 9 & 16.4 \\
Thought they had healed & 2 & 3.3 \\
\hline
\end{tabular}

In the present study, forgetfulness is a contributor to hypertensives non-adherence. This is due to the fact that the highest category was elderly patients. Elderly patients are known to forget to take their medicine, alter the schedule of the doses or overuse the drugs. This is consistent with the results from Ghana where patients reported forgetfulness as the main reason for non-adherence [64]. Forgetting to take drugs is a common problem in older people and especially when older people have several drugs to take.

Participants raised up the issue of lack of refill to antihypertensive treatment which is consistent with a previous study that revealed that lack of knowledge on effects of non-adherence, negative attitude to drugs, lack of time for refills and lack of family member support and cooperation on management contributes to non-adherence [65]. This calls for a focus on behavioral and social support aspect. Behavioural intervention move beyond the cognitive approaches of informational intervention to influence patients' behavior by shaping rewarding and reminding desired behavior, social intervention includes family members and others in supporting the medication adherence. Adequate and subsidized drugs if supplied to the hospital pharmacy would have reduced the cases of non-adherence. Overall managing hypertension is a behavior change practice that requires thoughtful knowledge efforts from all parties involved. The situation can also be revised by increased follow-ups and stricter advice by the medical practitioners including nurses, doctors, and pharmacists.

Figure 8 illustrates the other responses from the patients. When asked to indicate whether belonged to a health insurance scheme that caters for the medication bills, $48.1 \%$ of the respondents stated that they had invested in the scheme 


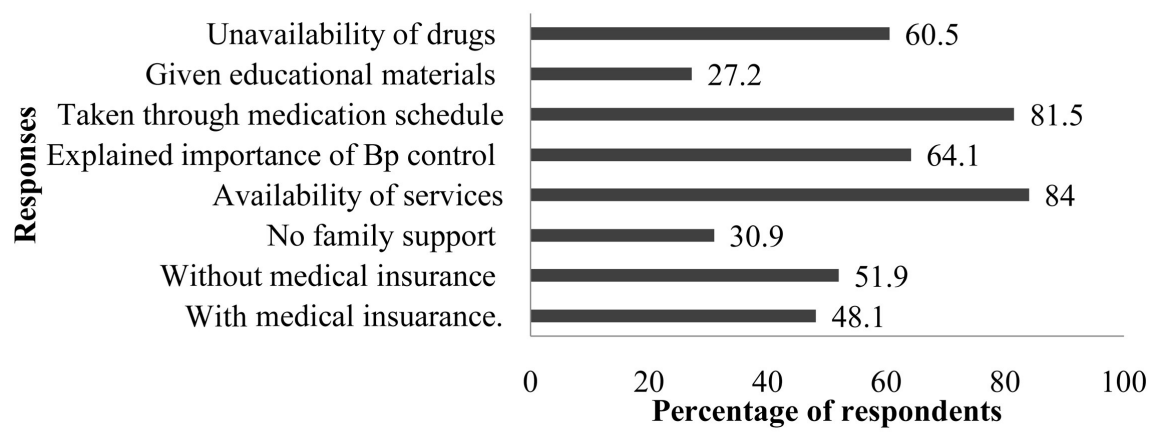

Figure 8. Other responses from patients $(n=81)$.

while $51.9 \%$ had no insurance. Further, the respondents (30.9\%) confirmed that they did not get family support in managing the condition. On availability of services, $84 \%$ of the respondents confirmed that the care providers were readily available to attend to them, explained the importance of B.P control (64.1\%), taken through the schedule of medication (81.5\%) although, only a few $(27.2 \%)$ benefitted from written patient health educational materials on hypertension. The respondents $(60.5 \%)$ further stated that most of the drugs prescribed by the doctors were unavailable in the hospital pharmacy hence making the patients source them from external chemists at exorbitant prices.

A study on relationship between adherence to antihypertensive medication regimen and out-of-pocket cost showed that medication non-adherence was more likely for those who paid higher out of pocket [66]. This is consistent with the study results as only $48.1 \%$ had a medical scheme and the majority of respondents revealed that non-adherence was due to inability to pay prescribed medicine, tests and lack of funds to enable access to the health facility. Patients with a high pill burden and those without family support were found to be non-adherence to antihypertensive medication. $30.9 \%$ of the respondents had no family support. Treatment partners and family support improves patient with chronic conditions [67]. Family support is the most accessible source of support system, therefore hypertension condition, which is a chronic condition, requires family support in its management and thus the study emphasizes the necessity of ensuring family support at the commencement and continuation of ant hypertensive therapy.

\subsection{Medical Staff Related Factors}

\subsubsection{Experience of the Medical Staff}

The study also sought to determine the duties and experiences of the medical staff that were sampled to participate in the study. As shown in Table 4, 40\% of the medical staff participants had served at the hypertension clinic for a period of between 1 - 5 years, $40 \%$ had worked in the clinic for between 5 and 10 years while $20 \%$ had worked in the clinic for a period of between 10 and 15 years.

The detection, diagnosis and treatment of hypertension require skills many of which are accumulated over a period of time. Skills also come in handy in the 
Table 4. Staff work experiences $n=10$.

\begin{tabular}{ccc}
\hline Period in years & Frequency & Percent \\
\hline $1-5$ & 4 & 40 \\
$5-10$ & 4 & 40 \\
$10-15$ & 2 & 20 \\
Total & 10 & 100 \\
\hline
\end{tabular}

detection of the cause of secondary hypertension as well as dealing with complications that arise as the disease advances. The study found that a majority (60\%) had served in the clinic for a period of over 5 years. Meaning they had adequate experience in management of hypertension and providing adequate advice to the patients. Hypertension directs attention to itself not only due to its prevalence but also due to the fact that it is asymptomatic, has diverse drugs and treatment procedures, requires long-time drug therapy, and demands to be followed up by the medical staff [68].

Table 5 presents the daily responsibilities of the medical staff at the hypertension clinic. Three main duties performed at the clinic emerged.

The results revealed that half the participants were allocated with the responsibility of treating and monitoring hypertensive patients 50\%. A section of the staff members $20 \%$ worked at the registry where they were involved in making records of the patients. Thirty percent $30 \%$ of the respondents handled hypertensive emergencies.

The results findings revealed that there was a multidisciplinary team that worked together in delivering hypertension care services with care purposed to certify individual needs. Team-based care in managing hypertension patients involved patients, nurses, physician's pharmacist and records officers. The professionals compliment the activities of the primary care provider by providing process support and sharing the responsibilities of hypertension care which includes medication management active patient follow up adherence and self-management support. Team-based hypertension care has been reported to increase the proportion of individuals to remain in care with controlled blood pressure [69].

\subsubsection{Challenge Facing the Medical Staffs}

The study further investigated on challenges facing the medical staff at the clinic and four main challenges emerged as shown in Table 6 . The challenges are; $40 \%$ stated that stock-outs of essential medicine for hypertensive patients, $10 \%$ felt that they had too many patients to handle, $10 \%$ cited low knowledge levels of patients on hypertension and $40 \%$ mentioned ignorance of patients. They pointed out that some individuals take half dosages or even stay without taking drugs for some time.

Findings of the study on stocks outs of antihypertensive medicines collaborate evidence from Tanzania where the review of availability of hypertensive drugs in year 2012-2013 pointed out stock-outs [70]. Access to essential medicines still 
Table 5. Duties of the medical staff $\mathrm{n}=10$.

\begin{tabular}{ccc}
\hline Duty & Frequency & Percent \\
\hline Treating/monitoring hypertensive patients & 5 & 50.0 \\
Registering and counseling patients & 2 & 20.0 \\
Management of hypertensive emergencies & 3 & 30.0 \\
\hline
\end{tabular}

Table 6. Challenges facing medical staff at the hypertensive clinic $n=10$.

\begin{tabular}{ccc}
\hline Challenges & Frequency & Percent \\
\hline Stock-outs of essential medicine for hypertensive patients & 4 & 40.0 \\
Low knowledge levels of patients on hypertension & 1 & 10.0 \\
Handling too many patients & 1 & 10.0 \\
Ignorance of patients/poor drug compliance & 4 & 40.0 \\
\hline
\end{tabular}

remains a challenge.

Stock-outs of hypertensive drugs disproportionately influence low-income patients as most often they cannot afford to travel looking for more affordable therapy due to high cost of transportation, for example. Low-income patients may most probably be unlikely to send supporters to buy the drugs in other markets due to lack of extra finances for transport cost and for purchase of drugs, hence the result to purchase of drugs at the nearby private-owned drugstore, which is the most costly alternative since it may be the only drug store in Chuka town. Some others forgot the drug that is out of stock and thus is left managing the condition with only the available prescribed regimen. Patients also explained that hypertension drugs were more affordable and at times issued out for free at the county health facilities.

Low knowledge or unawareness of hypertension and the asymptomatic nature of hypertension is the primary patient-related barrier [71]. The study findings are consistent with the results which revealed low knowledge on hypertension. Correct knowledge on elevated BP, its treatment and management creates understanding and prevents confusion. A study from Gaza and Pakistan revealed that individual who was knowledgeable about their disease and treatment had improved compliance to treatment compared to those who were less informed of their condition [72].

Though in contrary to the findings, studies from developed world showed no relationship between compliance and knowledge [73] [74].

In a study done in Western Kenya on barriers and facilitators to nurse management of HPT, nurses reported that there were inadequate training and excessive workload. They expressed concern on increased workload in the circumstance of present obligations and fear of further obligation associated with HPT management [71]. The result of this study reviewed that health care providers had too many patients to handle. Health care providers play a key role in the 
provision of health care services. The shortage of health care workers is partly due to the migration of health personnel's in search of better living standards, improved enumeration, access to advanced technology and failure of counties to replace those who left the institution. The shortages are diverse problems and improvements are needed if reduction of HPT-related morbidity is to be achieved. Shortage of staffs can explain the findings of the low knowledge of hypertension to patients because of the limited time that the health care worker is to stay with the patient.

Ignorance of patients on adherence to treatment was a predictive factor to patients attending the institution. The observed results on ignorance were also reported by Isezuo and Opera as being responsible for non-adherence in a study done in India on medication adherence rating of patients with hypertension [75]. Kaboru in his study on adherence to hypertensive treatment revealed that adherence was low in African countries and this was due to ignorance of severity and low knowledge of the treatment of hypertension [76]. The reasons for this challenge could be due to providing patients with non-comprehensive information or they may be having insufficient knowledge about the illness and the severity of its complications, making them not take seriously the recommendation given. Once the diagnosis is made patients should be educated on what is hypertension, its etiology, the length of treatment and the purpose for adherence to treatment, lifestyle changes and the need for sustained follow-up visits. Patients who have proper information on hypertension are more expected to accept the medication and follow health care providers' recommendations and are more unlikely to stop medications prematurely.

\subsubsection{Reasons for Non-Adherence According to Medical Staffs}

Health providers were asked what makes their patients miss drugs. According to the practitioners, the patient missed drugs because of ignorance (40\%), polypharmacy (10\%), denial (10\%), lack of transport (10\%), unaffordability of laboratory investigations and drugs $(20 \%)$, and intolerance to the side effect of the hypertension drugs (10\%).

Cost of medication and laboratory investigation are some of the explanations why individuals do not adhere to hypertensive drugs, this is consistent with a study done in Western Kenya on barriers and facilitators to nurse management in HPT which revealed that hypertensive medications were un-affordable [71]. Long standing conditions care management went further than the aggregate expenses of lifelong treatments; these include expenses related to laboratory testing, consultation, and transportation [71]. 54\% of participant in this study earned less than ksh. 10,000 per month and when a point biserial test was done it revealed positive correlation between monthly income and non-adherence to medication. Given the reality of low economic status in the form of monthly income and patients purchasing their own drugs out of their pocket was a barrier to the achievement of adherence.

Health providers reported that side effect is a contributing factor to non-ad- 
herence. The consequence of use of drug to patient makes them get afraid due to thinking that they may do more harm than good [77]. Unintended side effects felt by others or individually and fear concerning potential side effect impacts the behavior of adherence. When patients are mandated to select between side effects and control of asymptomatic ailment some patients may deliberately nonadhere [77]. Patients probably assessed the risk of the unintended side effect than by evaluating the circumstance [78]. Three-quarter of hypertensive patients in a study stated clinician/physician did not discuss the possible side effects that they were likely to experience [79].

Polypharmacy which is simultaneous use of multiple medications was a concern to some health care providers the results finding were consistent with a study by Palterson and others who found out that patient with chronic medical conditions are most susceptible to polypharmacy due to others taking more medication for their other medical disorders [80]. The use of numerous medicines is related to an increased risk of adverse effects which may even raise the danger of unwanted drug interaction for example a patient with angiotensin converting enzyme inhibitor which is antihypertensive drug and is also given potassium supplements can cause life-threatening elevations of potassium in the blood which requires emergency medical care. Patients with chronic conditions should be empowered to make informed decision about their drugs and other supplements they are taking and thus all health care providers have a vital role in empowering the patient to make these decisions.

Medical staffs revealed that lack of transport by patients was also a factor that influenced non-adherence. The longer distance was an obstacle to non-adherence to providers' advice particularly when it was accompanied by poor terrain and poverty. Medical staff continued to say that patients who came from far were more likely to be non-adherent as compared to patients who came from nearby. The study finding is consistent with a study in India which revealed that patient who took a long time for reviews were the poor and those who came from far [81].

\subsection{Measures to Adopt to Curb Non-Adherence}

When asked to state the measures that can be adopted to improve adherence to medication, the majority of the medical staff $(70 \%)$ felt that providing counseling services to patients would improve adherence to hypertension drugs. Effective counseling entails providing information on the condition, for instance, etiology, risk factors, complications, contraindication and side effects, promoting health status with adherence, and promoting healthy behaviors. It is crucial to highlight measures of risk factors thought to be contributing to non-adherence so as to improve in measures of controlling BP and to inform on risks of nonadherence to medication for example; risk factors to increased BP include; obesity, family history, alcohol, cigarette smoking, increasing age, sedentary life and diet with increased salt and fat. 
Patients require to be updated on management of hypertension, keeping an up-to-date record of their blood pressure numbers even when they are feeling fine. If it is normal in BP, they should continue managing it through the help of a health care provider. If it increases in BP, treatment may aid to avert injury to the organs in the body. Patients should be made aware of the notion of HPT and the effects on the blood vessels.

Health care counselors need to emphasize the implications of poor adherence, how alcohol use affects adherence, how to manage side effects, as well as stress the lifelong need for adherence. In particular, patients can be encouraged to utilize their social network as the high level of social support is allied with improved adherence. Adherence to medication would be a suitable strategy to minimise the cost of treatment since it minimises the cost of dealing with side effects resulting from non-adherence [82].

They also (20\%) felt that availability of more hypertension diagnostic equipment would aid in better diagnosing secondary hypertension. A considerable number of hypertensive patients have a risk of cardiovascular involvement at presentation time [83]. Early diagnosis and prompt treatment of HPT plays a significant role in reducing the dangers of stroke and cardiovascular disease. Both specialized and routine biochemical investigations are vital for examination of patients and subsequent management. The test aids in detecting the patients with greater risk of dysglycaemia, dyslipidemia, target organ damage, renal impairment, damage and eliminating recognizable causes of hypertension [83].

$\mathrm{MOH}$ Cardiovascular guideline recommends that a referral hospital should have, echo machines, blood analysis machines, cardiac catheterization lab, facilities for telemedicine and critical care unit among other equipment in other levels of care [31]. Health care providers felt that the equipment would help them in risk screening assessments and management of hypertensive patients.

Other (10\%) felt that the nurses should use mobile phones for making followups. Usage of mobile phones has extended among the communities [85]. Mobile phones are said to be the fastest adopted technology in high and low-income countries [84]. A new approach of model of managing health through phones is on increase. Quick adoption of smartphone technology generates an interesting and promising platform to overcome non-adherence to medication by offering healthy lifestyle education, providing drug intake reminders and keeping records of biometric measurements [84]. This strategy once adopted will overcome medication non-adherence by providing drug intake reminders and clinic follow-ups.

\subsection{Health System Related Factors and Non-Adherence to Medication}

The objective was to determine health system factors associated with non-adherence to hypertension medication in patients followed at Chuka referral hospital. Logistic regression was conducted to assess if health system related factors; quality of health service, physician patient relationship, stock out, health education and 
availability of medicine in the hospital. Hosmer-Lemeshow test was deployed to check for goodness-of-fit of the model, $\chi^{2}=11.99, d f=7, p=0.10$, which was not significant $(p>0.05)$, signifying that the model fit the data well. Hosmer and Lemeshow's measure $\left(R^{2}\right)$ was calculated as follows;

$$
\begin{aligned}
& R_{L}^{2} \frac{(-2 \mathrm{LL}(\text { baseline }))-(-2 \mathrm{LL}(\text { new }))}{-2 \mathrm{LL}(\text { baseline })} \\
& =\frac{105.673-103.588}{105.673} \\
& =0.020
\end{aligned}
$$

Table 7 presents the inferential statistical tests for overall model evaluation. The Hosmer and Lemeshow statistic $\left(R^{2}=0.02\right)$ indicates the model accounts for $2 \%$ of the variation on hypertension medication non-adherence as shown in Table 7 Nagelkerke $R^{2}$ estimate indicated that 3.5\% of the variance in non-adherence to hypertension medication can be predicted by health system related factors (quality of health service, physician patient relationship, stock out, health education and availability of medicine). Cox and Snell $R^{2}$ showed that the five factors can account for $2.5 \%$ of the variation. The health system related factors; quality of health service, physician patient relationship, stock out, health education and availability of medicine factors together are significant predictors of non-adherence to hypertension medication, $\chi^{2}=6.348, d f=1, \mathrm{n}=81, p<0.05$.

Table 8 presents the statistical significance of individual regression coefficients $\left(\beta_{\mathrm{s}}\right)$ tested using the Wald Chi-square statistic.

Table 7. Overall logistic regression model evaluation and goodness-of-fit statistics of predicting likelihood of non-adherence to medication $(n=81)$.

\begin{tabular}{ccccc}
\hline Test & $\mathrm{R}^{2}$ & $\chi^{2}$ & Df & $\mathrm{P}$ \\
\hline Overall model & & 6.348 & 1 & 0.012 \\
Hosmer and Lemeshow & 0.020 & 11.986 & 7 & 0.101 \\
Cox \& Snell & 0.025 & & \\
Nagelkerke & 0.035 & & \\
\hline
\end{tabular}

\begin{tabular}{|c|c|c|c|c|c|c|c|c|}
\hline \multirow{2}{*}{ Variable } & \multirow{2}{*}{$\beta$} & \multirow{2}{*}{$\begin{array}{l}\text { SE } \\
(\beta)\end{array}$} & \multirow{2}{*}{$\begin{array}{c}\text { Wald's } \\
\chi^{2}\end{array}$} & \multirow{2}{*}{ Df } & \multirow{2}{*}{$\mathrm{P}$} & \multirow{2}{*}{$\begin{array}{c}e^{\beta} \\
(\mathrm{OR})\end{array}$} & \multicolumn{2}{|c|}{$95 \%$ C.I } \\
\hline & & & & & & & Lower & Upper \\
\hline Quality of health service & 0.660 & 0.509 & 1.68 & 1 & 0.195 & 1.934 & 0.714 & 5.243 \\
\hline $\begin{array}{l}\text { Physician-patient } \\
\text { relationship }\end{array}$ & 0.412 & 0.594 & 0.482 & 1 & 0.488 & 1.510 & 0.472 & 4.838 \\
\hline Stock out & 0.063 & 0.450 & 0.020 & 1 & 0.888 & 1.065 & 0.441 & 2.572 \\
\hline health education & 0.162 & 0.594 & 0.074 & 1 & 0.785 & 1.176 & 0.367 & 3.769 \\
\hline Availability & 0.184 & 0.519 & 0.126 & 1 & 0.722 & 1.202 & 0.435 & 3.327 \\
\hline Constant & -2.74 & 1.901 & 2.08 & 1 & 0.149 & 0.064 & & \\
\hline
\end{tabular}

$p<0.05$.

Table 8. Coefficients of the model predicting non-adherence to medication $(\mathrm{n}=81)$. 
The results revealed that no individual health system related factors were a significant predictor of non-adherent to hypertension medication as the $p$-values were greater than the confidence interval $(p<0.05)$. The health system related factors; quality of health service $(p=0.20)$, physician patient relationship ( $p=$ $0.49)$, stock out $(p=0.89)$, health education $(p=0.79)$, and availability of medicine factors $(p=0.72)$. The health system related factors; quality of health service, physician patient relationship, stock out, health education and availability of medicine factors together are significant predictors of non-adherence to hypertension medication, $\chi^{2}=6.35, d f=1, \mathrm{n}=81, p=0.012$.

Null Hypothesis $\mathrm{H}_{01}$ : which stated that there is no statistically significant association between health systems associated factors and non-adherence to antihypertensive medication among patients followed at Chuka referral hospital. Using the level of significance as $5 \%$ and 1 degree of freedom in chi-square table the critical value of chi-square statistics is 3.84 and the calculated/test chi-square is $\chi^{2}=6.34, p=0.012$ ) which is greater than critical value proves that is statistically significant association between health system associated factors and nonadherence and hence null hypothesis is rejected.

Prove from the result findings is that health related factors contributed towards non-adherence to hypertensive medication. Health systems factors play a crucial role in the promotion of adherence. A good link between patient and health care provider which comprises reinforcement and encouragement from the health worker has a positive influence on compliance to drugs. Study findings from Ethiopia at university of Gondor hospital indicated a positive relationship between nonperfect adherence to medication and poor physician-patient relationship [85]. The results indicated that health education precisely on hypertension treatment including the use of drugs with fewer side-effects, and probe of potential side-effects the individual may have resulted in adherence improvement.

In low-income countries provision of drugs in health facilities are scarce and thus the majority of patients end up buying from their out of pocket. A recent study revealed that availability of drugs prescribed during hypertension clinic and the cost were predictors of health seeking behavior [8]. Approaches for refining access to drugs, for instance, reliable supply, sustainable financing and subsidized prices have a significant effect on patient adherence and mainly in low-income segments of the population [86]. Hence focus on improving the efficiency of health system functions like financing delivery of care and appropriate medication management can create a significant influence to promoting the adherence rates of hypertensive patients.

\section{Conclusions}

Non-adherence to hypertension medication is a major problem at Chuka level five hospital. The majority of the individuals diagnosed with hypertension have been missing medication. Most of the drugs prescribed by the doctors were un- 
available in the hospital pharmacy hence making the patients source them from external chemists at exorbitant prices. To practitioners, non-adherence to hypertension medication resulted from stock out and ignorance on the part of the patients. The absence of hypertensive drugs influences poorer patients due to a lack of funds to access cheaper drugs and high charges of transport. Low-income patients may also be unlikely to send supporters to purchase the drugs in towns or markets.

It is clear that individuals with low-income levels and elderly patients are more likely not to comply with HPT drugs than young and those with high monthly income. Education level did correlate with non-adherence to hypertensive medication. However, many of the patients knew how to read and write, hence capable of following doctor's directions and adhering to hypertension medication. Despite the high levels of non-adherence, the care providers were readily available to attend to them, explained to them the importance of B.P control, took them through the schedule of medication and gave health educational materials on hypertension to some.

The study identified three strategies that can be adopted to minimize if not eradicate non-adherence. First, effective counselling should be adopted to change the behavior of the patients. This would entail providing facts on side effects and contraindications, enhancing health status with medication adherence, providing facts on side effects and contraindications, and supporting healthy behaviors. Secondly, the availability of more hypertension medication equipment would also help to reverse the situation and lastly facilitating the practitioners to make adequate, regular and sustained follow-ups. Health system related factors; quality of health services, physician patient relationship, stock out, health education and availability of medicine factors were revealed to be important predictors of hypertension medication non-adherence. However, no individual factor in the health system was a significant predictor of non-adherent to hypertension medication.

\section{Conflicts of Interest}

The authors declare no conflicts of interest regarding the publication of this paper.

\section{References}

[1] Lim, S.S., Vos, T., Flaxman, A.D., Danaei, G., Shibuya, K., Adair-Rohani, H., Aryee, M., et al. (2013) A Comparative Risk Assessment of Burden of Disease and Injury Attributable to 67 Risk Factors and Risk Factor Clusters in 21 Regions, 1990-2010: A Systematic Analysis for the Global Burden of Disease Study 2010. The Lancet, 380, 2224-2260.

[2] Crim, M.T., Yoon, S.S. and Ortiz, E. (2012) National Surveillance Definitions for Hypertension Prevalence and Control among Adults. Cardiovascular Quality and Outcomes, 5, 343-351. https://doi.org/10.1161/CIRCOUTCOMES.111.963439

[3] Forouzanfar, M.H., Liu, P., Roth, G.A., Ng, M., Biryukov, S., Marczak, L. and Ali, R. 
(2017) Global Burden of Hypertension and Systolic Blood Pressure of at Least 110 to $115 \mathrm{Mm} \mathrm{Hg}, 1990-2015$. JAMA, 317, 165-182.

https://doi.org/10.1001/jama.2016.19043

[4] Persell, D. (2011) Prevalence of Resistant Hypertension in the United States, 20082012. Hypertension Journal, 57, 1076-1080.

https://doi.org/10.1161/HYPERTENSIONAHA.111.170308

[5] World Health Organization (2019)

https://www.who.int/News-Room\%20Factsheet/Detail/Hypertension

[6] World Health Organization (2017) Global Health Observatory Data Raised Blood Pressure.

http://www.Who.Int/Gho/Ncd/Risk_Factors/Blood_Pressure_Prevalence_Text/En (Updated 2017)

[7] World Health Organization (2012) Kenya Who Statistical Profile. http://www.Who.Int/Gho/Countries/Ken.Pdf?Ua=1 (Updated 2012)

[8] Mwenda, K., Kirigia, C., Kamweru, P.K. and Gitonga, L.K. (2020) Factors Affecting Health Seeking Behaviour in Hypertensive Patients of Imenti North Sub County, Kenya. International Journal of Community Medicine and Public Health, 8, 37-42. https://doi.org/10.18203/2394-6040.ijcmph20205675

[9] Dragomir, A., Cote, R., Roy, L., Blais, L., Lalonde, L., Bérard, A. and Perreault, S. (2010) Impact of Adherence to Antihypertensive Agents on Clinical Outcomes and Hospitalization Costs. Medical Care, 48, 418-425. https://doi.org/10.1097/MLR.0b013e3181d567bd

[10] Jaffe, M.G., Frieden, T.R., Campbell, N.R., Matsushita, K., Appel, L.J., Lackland, D.T. and Whelton, P.K. (2018) Recommended Treatment Protocols to Improve Management of Hypertension Globally: A Statement by Resolve to Save Lives and the World Hypertension League (WHL). The Journal of Clinical Hypertension, 20, 829-836. https://doi.org/10.1111/jch.13280

[11] Primatesta, P. and Poulter, N.R. (2006) Improvement in Hypertension Management in England: Results from the Health Survey for England. Journal of Hypertension, 24, 1187-1192. https://doi.org/10.1097/01.hjh.0000226210.95936.bc

[12] Hashmi, S.K., Afridi, M.B., Abbas, K., Sajwani, R.A., Saleheen, D., Frossard, P.M. and Ahmad, U. (2007) Factors Associated with Adherence to Anti-Hypertensive Treatment in Pakistan. PLoS ONE, 2, e280. https://doi.org/10.1371/journal.pone.0000280

[13] De Simoni, A., Hardeman, W. and Mant, J. (2013) Trials to Improve Blood Pressure through Adherence to Antihypertensive in Stroke/TIA: Systematic Review and Meta-Analysis. Journal of the American Heart Association, 2, 1-8. https://doi.org/10.1161/JAHA.113.000251

[14] Brinker, S., Pandey, A. and Ayers, C. (2014) Therapeutic Drug Monitoring Facilitates BP Control in Resistant Hypertension. Journal of the American College of Cardiology, 63, 834-835. https://doi.org/10.1016/j.jacc.2013.10.067

[15] Corrao, G., Parodi, A. and Nicotra, F. (2011) Better Compliance to Antihypertensive Medications Reduces Cardiovascular Risk. Journal of Hypertension, 29, 610-618. https://doi.org/10.1097/HJH.0b013e328342ca97

[16] Perreault, S., Yu, A.Y. and Côté, R. (2012) Adherence to Antihypertensive Agents after Ischemic Stroke and Risk of Cardiovascular Outcomes. Neurology Journal, 79, 2037-2043. https://doi.org/10.1212/WNL.0b013e3182749e56

[17] WHO (2013) Global Status Report on Non-Communicable Diseases 2013: Attaining the Nine Global Non-Communicable Diseases Targets; a Shared Responsibility. 
[18] Panjabi, S., Lacey, M., Bancroft, T. and Cao, F. (2012) Treatment Adherence, Clinical Outcome and Economic of Triple Drug Therapy in Hypertensive Patients. Journal of American Society of Hypertension, 7, 46-60. https://doi.org/10.1016/j.jash.2012.11.001

[19] Kronish, I.M. and Ye, S. (2013) Adherence to Cardiovascular Medications: Lessons Learned and Future Directions. Progress in Cardiovascular Diseases, 55, 590-600. https://doi.org/10.1016/j.pcad.2013.02.001

[20] Arshia, B., Mehwish, R., Noor-Ulain, S., Mariam, A., Sadaf, S. and Rasheed, S. (2010) Non-Compliance to Anti-Hypertensive Medication and Its Associated Factors among Hypertensives. Karachi Medical and Dental College, Karachi.

[21] Mathenge, W., Foster, A. and Kuper, H. (2010) Urbanization, Ethnicity and Cardiovascular Risk in a Population in Transition in Nakuru, Kenya: A Population-Based Survey. BMC Public Health, 10, 569. https://doi.org/10.1186/1471-2458-10-569

[22] Atinga, R.A., Yarney, L. and Gavu, N.M. (2018) Factors Influencing Long-Term Medication Non-Adherence among Diabetes and Hypertensive Patients in Ghana: A Qualitative Investigation. PLoS ONE, 13, e0193995. https://doi.org/10.1371/journal.pone.0193995

[23] Buckley, L., Labonville, S. and Barr, J. (2016) A Systematic Review of Beliefs about Hypertension and Its Treatment among African Americans. Current Hypertension Reports, 18, 52. https://doi.org/10.1007/s11906-016-0662-5

[24] Lewis, L. (2012) Factors Associated with Medication Adherence in Hypertensive Blacks: A Review of the Literature. Journal of Cardiovascular Nursing, 27, 208-219. https://doi.org/10.1097/JCN.0b013e318215bb8f

[25] Bruce, S., Acheampong, F. and Kretchy, I. (2015) Adherence to Oral Anti-Diabetic Drugs among Patients Attending a Ghanaian Teaching Hospital. Pharmacy Practice, 13, 533. https://doi.org/10.18549/PharmPract.2015.01.533

[26] Wu, J.R., Lennie, T.A., Chung, M.L., Frazier, S.K., Dekker, R.L., Biddle, M.J. and Moser, D.K. (2012) Medication Adherence Mediate the Relationship between Marital Status and Cardiac Event-Free Survival in Patients with Heart Failure. Heart and Lung-The Journal of Acute And Critical Care, 41, 107-114.

https://doi.org/10.1016/j.hrtlng.2011.09.009

[27] Zyoud, S.H., Al-Jabi, S.W., Sweileh, W.M. and Morisky, D.E. (2013) Relationship of Treatment Satisfaction to Medication Adherence: Findings from a Cross-Sectional Survey among Hypertensive Patients in Palestine. Health and Quality of Life Outcomes, 11, 191-197. https://doi.org/10.1186/1477-7525-11-191

[28] Mcmullen, C., Safford, M., Bosworth, H., Phansalkar, S., Leong, A. and Fagan, M.B. (2015) Patient-Centered Priorities for Improving Medication Management and Adherence. Patient Education and Counseling, 98, 102-110. https://doi.org/10.1016/j.pec.2014.09.015

[29] WHO (2012) Clinical Guidelines for the Management of Hypertension. World Health Organization, Cairo.

[30] Kioko, J. (2017) Government Unveils Strategies to Control Hypertension, the Silent Killer. Ministry of Health, Nairobi.

[31] Ministry of Health Kenya (2018) Kenya National Guidelines for Cardiovascular Diseases Management.

[32] Al-Khaldi, Y.M. and Al-Sharif, A.I. (2005) Health Education Resources Availability for Diabetes and Hypertension at Primary Care Settings, Aseer Region, Saudi Arabia. Journal of Family and Community Medicine, 12, 75. 
[33] Baune, B. and Aljeesh, Y. (2006) The Association of Psychological Stress and Health Related Quality of Life among Patients with Stroke and Hypertension in Gaza Strip. Annals of General Psychiatry, 5, 6.

[34] Zolnierek, K.B.H. and Dimatteo, M.R. (2009) Physician Communication and Patient Adherence to Treatment: A Meta-Analysis. Medical Care, 47, 826-834. https://doi.org/10.1097/MLR.0b013e31819a5acc

[35] Schoenthaler, A., Chaplin, W.F., Allegrante, J.P., Fernandez, S., Diaz-Gloster, M., Tobin, J.N. and Ogedegbe, G. (2012) Effects of Patients Provider Communication on Medication Adherence in Hypertensive Black Patients: Does Race Concordance Matter? https://doi.org/10.1007/s12160-011-9342-5

[36] Cane. J., O’Connor, D. and Michie, S. (2012) Validation of the Theoretical Domains Framework for Use in Behavior Change and Implementation Research. Implementation Science, 24, 37. https://doi.org/10.1186/1748-5908-7-37

[37] Craig, H.M. (1985) Accuracy of Indirect Measures of Medication Compliance in Hypertension. Research in Nursing and Health, 8, 61-66.

https://doi.org/10.1002/nur.4770080112

[38] Haynes, R.B., Ackloo, E., Sahota, N., Mcdonald, H.P. and Yao, X. (2008) Intervention for Enhancing Medication Adherence. Cochrane Database of Systematic Reviews, 2, CD00011. https://doi.org/10.1002/14651858.CD000011.pub3

[39] Ley, P. (1988) Communicating with Patients: Improving Communication, Satsfaction and Compliance. Croom Helm, New York.

[40] Michie, S., Van Stralen, M.M. and West, R. (2011) The Behaviour Change Wheel: A New Method for Characterising and Designing Behaviour Change Interventions. Implement Science, 6, 42. https://doi.org/10.1186/1748-5908-6-42

[41] Clinical Effectiveness Research Agenda Group (CERAG) (2008) An Implementation Research Agenda: A Report Prepared for the High Level Group on Clinical Effectiveness. CERAG, London.

[42] Newman, M., Papadopoulous, L. and Sigsworth, J. (1998) Barriers to Evidence-Based Practice. Clinical Effectiveness in Nursing, 2, 11-18. https://doi.org/10.1016/S1361-9004(98)80080-0

[43] Grol, R. and Grimshaw, J. (2003) From Evidence to Best Practice: Effective Implementation of Change in Patients' Care. The Lancet, 362, 1225-1230.

https://doi.org/10.1016/S0140-6736(03)14546-1

[44] Abraham, C., Kelly, M.P., West, R. and Michie, S. (2009) The UK National Institute for Health and Clinical Excellence Public Health Guidance on Behavior Change: A Brief Introduction. Psychology, Health and Medicine, 14, 1-8. https://doi.org/10.1080/13548500802537903

[45] Noar, S.M. and Zimmerman, R.S. (2009) Health Behavior Theory and Cumulative Knowledge Regarding Health Behaviors: Are We Moving in the Right Direction. Health Education Research: Theory and Practice, 20, 275-290. https://doi.org/10.1093/her/cyg113

[46] Salaria, N. (2012) Meaning of the Term Descriptive Survey Research Method. International Journal of Transmission in Business Management, 16, 1-7.

[47] Nassiuma, D.K. (2000) Survey Sampling: Theory and Methods. Nairobi University Press, Nairobi.

[48] Chuka Referral Hospital (2016) Chuka Referral Hospital Morbidity Report for Year 2016.

[49] Nagelkerke, N.J.D. (I991) A Note on General Definitions of the Coefficient of De- 
termination. Biometrika, 78, 691-692. https://doi.org/10.1093/biomet/78.3.691

[50] Courtenay, W.H. (2000) Constructions of Masculinity and Their Influence on Men's Well-Being: A Theory of Gender and Health. Social Science and Medicine Journal, 50, 1385-1401. https://doi.org/10.1016/S0277-9536(99)00390-1

[51] Silva, S., Oliveira, S. and Pierin, A.M.G. (2016) The Control of Hypertension in Men and Women: A Comparative Analysis. Revista Da Escola De Enfermagem Da USP, 50, 50-58. https://doi.org/10.1590/S0080-623420160000100007

[52] Thompson, A.E., Anisimowicz, Y., Miedema, B., Hogg, W., Wodchis, W.P. and Aubrey-Bassler, K. (2016) The Influence of Gender and Other Patient Characteristics on Health Care-Seeking Behaviour. BMC Family Practice, 17, 38. https://doi.org/10.1186/s12875-016-0440-0

[53] Li, W.W., Wallhagen, M.I. and Froelicher, E.S. (2008) Hypertension Control, Predictors for Medication Adherence and Gender Differences in Older Chinese Immigrants. Journal of Advanced Nursing, 61, 326-335. https://doi.org/10.1111/j.1365-2648.2007.04537.x

[54] Demonceau, J., Ruppar, T., Kristanto, P., et al. (2013) Identification and Assessment of Adherence-Enhancing Interventions in Studies Assessing Medication Adherence through Electronically Compiled Drug Dosing Histories: A Systematic Literature Review and Meta-Analysis. Drugs, 73, 545-562.

https://doi.org/10.1007/s40265-013-0041-3

[55] Trivedi, R.B., Ayotte, B., Edelman, D. and Bosworth, H.B. (2008) The Association of Emotional Well-Being and Marital Status with Treatment Adherence among Patients with Hypertension. Journal of Behavioral Medicine, 31, 489-497.

https://doi.org/10.1007/s10865-008-9173-4

[56] Chung, M., Lennie, T., Riegel, B., Wu, J., Dekker, R. and Moser, D. (2009) Marital Status as an Independent Predictor of Event-Free Survival of Patients with Heart Failure. American Journal of Critical Care, 18, 562-570. https://doi.org/10.4037/ajcc2009388

[57] Vincent, B., Adebowale, A., Francis, A., Aina, O. and Ezenwafor, O. (2015) Factors Associated with Medication Non-Adherence among Hypertensive in Ghana and Nigeria. International Journal of Hypertension, 2015, Article ID: 205716.

[58] Ibrahim, S.A. (2003) Hypertension and Medication Adherence among African Americans: A Potential Factor in Cardiovascular Disparities. Journal of the National Medical Association, 95, 28-29.

[59] Shaw, R. and Bosworth, H.B. (2012) Baseline Medication Adherence and Blood Pressure in a 24 Month Longitudinal Hypertension Study. Journal of Clinical Nursing, 21, 1401-1406. https://doi.org/10.1111/j.1365-2702.2011.03859.x

[60] Després, F., Perreault, S., Lalonde, L., Forget, A., Kettani, F.-Z. and Blais, L. (2014) Impact of Drug Plans on Adherence to and the Cost of Antihypertensive Medications among Patients Covered by a Universal Drug Insurance Program. The Canadian Journal of Cardiology, 30, 560-567. https://doi.org/10.1016/j.cjca.2013.11.032

[61] Goldman, D.P., Joyce, G.F. and Zheng, Y. (2007) Prescription Drug Cost Sharing: Associations with Medication and Medical Utilization and Spending and Health. The Journal of the American Medical Association, 298, 61-69. https://doi.org/10.1001/jama.298.1.61

[62] Bagonza, J., Rutebemberwa, E. and Bazeyo, W. (2015) Adherence to Anti Diabetic Medication among Patients with Diabetes in Eastern Uganda; a Cross Sectional Study. BMC Health Services Research, 15, 168. https://doi.org/10.1186/s12913-015-0820-5 
[63] Park, Y.H., Kim, H., Jang, S.-N. and Koh, C.K. (2013) Predictors of Adherence to Medication in Older Korean Patients with Hypertension. European Journal of Cardiovascular Nursing, 12, 17-24. https://doi.org/10.1016/j.ejcnurse.2011.05.006

[64] Jambedu, H.A. (2006) Adherence to Antihypertensive Medication among Patients Attending the G.P.H.A Hospital in Tokoradi Ghana.

[65] Grueninger US (1995) Arterial Hypertensionlesson from Patients Education. Patient Education and Counseling, 26, 37-55. https://doi.org/10.1016/0738-3991(95)00750-T

[66] Bailer-Goering, M.M. and Royk, H.D.H. (2019) Relationship between Adherence to Antihypertensives Medication Regimen and out of Pocket Cost among People Aged 35-64 with Employer Sponsored Health Insurance. Preventing Chronic Disease, 16, 180-381. https://doi.org/10.5888/pcd16.180381

[67] Olowookere, A.J., Olowookere, S.A., Talabi, A.O., Entonyeaku, A.C., Adeleke, O.E. and Aikuboboje, O.O. (2015) Perceived Family Support and Factors Influencing Medication Adherence among Hypertensive Patients Attending a Nigerian Tertiary Hospital. Annals of Tropical Medicine and Public Health, 8, 241-245. https://doi.org/10.4103/1755-6783.162668

[68] Kearney, P.M., Whelton, M., Whelton, P.K., Reynolds, K., Muntner, P. and He, J. (2005) Global Burden of Hypertension: Analysis of Worldwide Data. The Lancet, 365, 217-223. https://doi.org/10.1016/S0140-6736(05)17741-1

[69] Clark, C.E., Smith, L.F. and Taylor, J.L. (2010) Nurses Led Intervention to Improve Control of Blood Pressure in People with Hypertension. BMJ, 341, c3995.

[70] Robertson, J., Mace, C., Forte, G., Dejoncheere, K. and Beran, D. (2015) Medicines Availability for Non-Communicable Diseases: The Case of Standardized Monitoring. Globalization and Health, 11, 35. https://doi.org/10.1186/s12992-015-0120-1

[71] Rajesh, V., Nelly, T., Clare, K., Evans, B., Jemima, K., Violet, N., Sylvester, T., Carol, H. and Valentin, F. (2016) Barriers and Facilitators to Nurse Management of Hypertension: A Qualitative Analysis from Western Kenya. Ethnicity \& Disease, 26, 315-322. https://doi.org/10.18865/ed.26.3.315

[72] Beune, E.J., Charante, E.P., Beem, L., Mohrs, J., Agyemang, C.O., Ogedegbe, G. and Haafkens, J.A. (2014) Culturally Adapted Hypertension Education (CAHE) to Improve Blood Pressure Control and Treatment Adherence in Patients of African Origin with Uncontrolled Hypertension: Cluster-Randomized Trial. PLoS ONE, 9, e90103. https://doi.org/10.1371/journal.pone.0090103

[73] Krousel-Wood, M., Thomas, S., Muntenes, P. and Morisky, D. (2004) Medication Adherence a Key Factor in Achieving BP Control and a Good Clinical Outcome in Hypertension Patient. Current Opinion in Cardiology, 19, 357-362. https://doi.org/10.1097/01.hco.0000126978.03828.9e

[74] Cokkinos, D.V., Mountokalakis, Td., et al. (2005) Adherence to Antihypertensive Treatment: A Critical Factor for Blood Pressure Control. European Journal of Cardiovascular Prevention \& Rehabilitation, 12, 243-249. https://doi.org/10.1097/01.hjr.0000160601.41762.44

[75] Isezuo, A.S. and Opera, T.C. (2000) Hypertension Awareness among Nigerians in a Nigeria Tertiary Health Institution. Sahel Medical Journal, 3, 93-9622.

[76] Kaboru, B. (2013) Patients-Related Predictors of Poor Adherence to Antihypertensive Treatment in Congo-Brazzaville: A Cross-Sectional Study. Global Journal of Medicine and Global Health, 2, 1-9.

[77] Marie, I., Jerniffer, B., Supana, D. and Catherine, D. (2016) Medication Adherence 
Truth and Consequences. The American Journal of the Medical Sciences, 351, 387-399. https://doi.org/10.1016/j.amjms.2016.01.010

[78] Paling, J. (2003) Strategies to Help Patient Understand Risks. BMJ, 327, 745-748. https://doi.org/10.1136/bmj.327.7417.745

[79] Lapane, K.L., Dube, C.E., Schreider, K.L. and Quilliam, B.J. (2007) Mis-Perception of Patients vs Providers Regarding Medication Related Communication Issues. The American Journal of Managed Care, 13, 613-618.

[80] Palterson Sm Cadogai, C.A., Kersee, N., Cardwell, C.R., Bradaey, M.C., Ryan, C. and Huges (2014) Intervention to Improve the Appropriate Use of Poly Pharmacy for Older People. The British Medical Journal, 326, 450-459.

[81] Inkster, M.E., Donnan, P.T., Macdonald, T.M., Sullivan, F.M. and Fahey, T. (2006) Adherence to Antihypertensive Medication and Association with Patient and Practice Factors. Journal of Human Hypertension, 20, 295-297. https://doi.org/10.1038/sj.jhh.1001981

[82] Osterberg, L. and Blaschke, T. (2005) Adherence to Medication. The New England Journal of Medicine, 353, 487-497. https://doi.org/10.1056/NEJMra050100

[83] Shea, O., Griffin, T. and Fitzigibbon, M. (2016) The Role of Biochemistry in Diagnosis and Management. Clinica Chimica Acta, 465, 131-143.

[84] Anglada Martinez, H., Riuviladoms, G., Martin Conds, M., Roviraillamola, M., Sotoca-Mombiana, J.M. and Codin, J.C. (2015) Does Health Increase Adherence to Medication. Results of a Systematic Review. International Journal of Clinical Practice, 69, 9-32. https://doi.org/10.1111/ijcp.12582

[85] Ambaw, A.D., Alemie, G.A. and Mengesha, Z.B. (2012) Adherence to Antihypertensive Treatment and Associated Factors among Patients on Follow up at University of Gondar Hospital, Northwest Ethiopia. BMC Public Health, 12, 282. https://doi.org/10.1186/1471-2458-12-282

[86] Schafheutle, E.I., Hassell, K., Noyce, P.R. and Weiss, M.C. (2002) Access to Medicines: Cost as an Influence on the Views and Behaviour of Patients. Health and Social Care in the Community, 10, 187-195.

https://doi.org/10.1046/j.1365-2524.2002.00356.x 